\title{
PENERAPAN METODE GOAL PROGRAMMING DALAM MENGOPTIMALKAN PENDISTRIBUSIAN BBM di KOTA POSO SERTA MEMINIMUMKAN KENDARAAN YANG DIGUNAKAN BERBASIS KAPASITAS TANGKI SPBU
}

\author{
Hasbi ${ }^{1}$, A.I. Jaya ${ }^{2}$, dan R. Ratianingsih ${ }^{3}$ \\ 1,2,3 Jurusan Matematika, Fakultas Matematika dan IImu Pengetahuan Alam \\ Universitas Tadulako \\ Jalan Soekarno-Hatta Km. 9 Palu 94118, Indonesia \\ 1hasbi_mipa@yahoo.com, 2jayaindraagus@gmail.com, 3ratianingsih@yahoo.com
}

\begin{abstract}
PT. Pertamina UPMS VII fuel terminal of Poso Group is one branch of PT. Pertamina, which is responsible to maximize distribution of fuel in Poso city, Central Sulawesi. In addition to maximize distribution, PT. Pertamina UPMS VII fuel terminal of Poso Group should also has to minimize quantity of trucks that used based on the tank capacity gas station. To optimize the distribution, it needs a method that can solve the problems with more than one goals, that is Goal Programming method. Model formulation of Goal Programming consists of 4 priorities and 3 constraints functions. Those priorities are the tank capacity at PT. Trioceles Utama, PT. Arjuna M Setia, and PT. Mr. Lucky Lasahido, as well as the number of trucks. As for the function constraints are quality of distribution of BBM to each gas station, capacity $8000 \mathrm{I}$ and $16000 \mathrm{I}$ truck, and capacity $16000 \mathrm{l}$. From the results, based on the SPBU tank capacity, the optimal fuel supply that can satisfy the fuel distribution for a month are $1.156 .000 /$ for premium, 964.000 /for solar, dan 352.000 / for pertamax. For fuel distribution, it needs 9 trucks (5 trucks with 8,000 $l$ of capacity and 4 trucks with 16,000 $l$ of capacity) for premium, 4 trucks with 16,000 $l$ of capacity for solar, 6 trucks with $8,000 l$ of capacity for pertamax.
\end{abstract}

Keyword : : Goal Programming , Optimum Distribution, Pertamax, Premium, Solar, Truck capacity.

\section{ABSTRAK}

PT. Pertamina Upms VII terminal BBM Poso Group merupakan salah satu cabang PT. Pertamina yang bertanggung jawab untuk memaksimalkan penyaluran BBM di Kota Poso, Sulawesi Tengah. Selain memaksimalkan penyaluran, PT. Pertamina Upms VII terminal BBM Poso Group juga harus meminimumkan jumlah truk yang digunakan sesuai dengan kapasitas tangki SPBU. Untuk menggoptimalkan penyaluran tersebut dibutuhkan suatu metode yang dapat menyelesaikan persoalan dengan tujuan lebih dari satu yaitu metode Goal Programming. Formulasi model Goal Programming terdiri dari 4 prioritas dan 3 fungsi kendala. Prioritas-prioritas tersebut adalah Kapasitas tangki SPBU di PT. Trioceles Utama, PT. Arjuna M Setia, dan PT. Mr. Lucky Lasahido, serta jumlah truk yang digunakan. Adapun fungsi kendalanya yaitu banyaknya penyaluran BBM ke masing-masing SPBU, truk kapasitas 8000 /, dan truk berkapasitas 16000 /. Dari hasil penelitian, didapatkan persediaan BBM optimal, berdasarkan kapasitas tangki SPBU, yang dapat memenuhi penyaluran BBM selama 1 bulan, yaitu 1.156.000 / untuk premium, 964.000 / untuk solar, dan 352.000 / untuk pertamax. Untuk pendistribusian BBM adalah 
sebanyak 9 unit truk untuk premium (5 unit truk berkapasitas $8.000 /$ dan 4 truk berkapasitas $16.000 /, 4$ unit truk berkapasitas 16.000 / untuk solar, dan 6 unit truk berkapasitas 8.000 / untuk pertamax.

Kata Kunci : : Goal Programming , Pendistribusian Optimal, Pertamax, Premium, Solar, Kapasitas Truk.

\section{PENDAHULAN}

\subsection{Latar Belakang}

Sebagai salah satu negara yang masih sangat bergantung akan BBM, isu BBM ini akan selalu menarik untuk diperbincangkan. Sebagian besar warga dilndonesia hidupnya sangat bergantung akan BBM hampir semua kebutuhan dipenuhi oleh sumber energi fosil yang satu ini. Hal itu bukanlah masalah bagi Indonesia dimasa lampau, karena dahulu Indonesia merupakan salah satu negara penghasil dan pengekspor minyak. Banyak negara-negara bergantung akan pasokan minyak dari Indonesia. (Ariadji, 2014)

Pertamina sebagai suatu perusahaan yang bergerak dalam bidang penyediaan sekaligus penyalur BBM harus menjaga persediaan bahan bakar yang cukup untuk kebutuhan masyarakat. Namun dalam mengoptimalkan persediaan BBM tersebut, Pertamina juga harus mempertimbangkan mengenai jumlah BBM yang disalurkan, sehingga tidak melebihi kuota yang telah ditetapkan. Untuk itu diperlukan suatu metode yang dapat mengoptimalkan penyaluran keberbagai daerah, agar tiap daerah mendapatkan pasokan BBM yang sesuai dengan kebutuhan.

Salah satu metode untuk menyelesaikan masalah tersebut adalah dengan menggunakan metode Goal Programming. Metode Goal Programming merupakan modifikasi atau variasi khusus program linier. Analisis Goal Programming bertujuan untuk meminimumkan jarak antara atau deviasi terhadap tujuan, target atau sasaran yang telah ditetapkan dengan usaha yang dapat ditempuh. Untuk mencapai target atau tujuan tersebut secara maksimal harus sesuai dengan syarat yang membatasinya, berupa sumber daya yang tersedia, teknologi yang ada, kendala tujuan, dan sebagainya.

PT. Pertamina Unit Pemasaran VII Terminal BBM Poso Group dijadikan studi kasus dalam penelitian ini, sehingga masalah pengoptimalan penyediaan BBM subsidi dan nonsubsidi agar tidak melebihi kuota dan sesuai dengan jumlah kendaraan yang ada di Poso kota menjadi fokus penelitian.

Berdasarkan uraian diatas maka penulis tertarik untuk melakukan penelitian dengan mengangkat judul "Penerapan Metode dalam Mengoptimalkan Pendistribusian BBM di Kota Poso serta Meminimumkan Kendaraan yang digunakan Berbasis Kapasitas Tangki SPBU ". 


\subsection{Rumusan Masalah}

Adapun rumusan masalah berdasarkan latar belakang yang telah diuraikan diatas adalah menentukan banyaknya penyaluran yang optimal sesuai dengan kapasitas tangki SPBU, serta meminimumkan kendaraan yang digunakan agar penyaluran BBM dikota Poso dapat optimal dengan menggunakan metode Goal Programming.

\subsection{Tujuan Penelitian}

Tujuan dari penelitian ini adalah untuk mendapatkan banyaknya penyaluran yang optimal sesuai dengan kapasitas SPBU, serta meminimumkan kendaraan yang digunakan agar penyaluran BBM optimal di Kota Poso dengan menggunakan metode Goal Programming.

\subsection{Batasan Masalah}

Adapun batasan masalah pada penetian ini yaitu :

1. Penyaluran BBM yang diteliti hanya sebatas wilayah Kota Poso.

2. Jenis BBM yang diteliti adalah Premium, Solar dan Pertamax.

\section{METODE PENELITIAN}

\subsection{Prosedur Penelitian}

Adapun prosedur penelitian ini adalah sebagai berikut :

1. Mulai penelitian.

2. Pengambilan data.

3. Membangun Model Matematika dari data yang diperoleh.

Model matematika adalah suatu cara sederhana untuk menerjemahkan suatu masalah kedalam bahasa matematika dengan menggunakan persamaan, pertidaksamaan, atau fungsi.

4. Menyelesaikan model matematika tersebut dengan menggunakan metode Goal Proramming.

Goal programming merupakan modifikasi atau variasi khusus dari program linear yang sudah kita kenal. Analisis Goal Programming bertujuan untuk meminimumkan jarak antara atau deviasi terhadap tujuan, target atau sasaran yang telah ditetapkan dengan usaha yang dapat ditempuh untuk mencapai target atau tujuan tersebut secara memuaskan sesuai dengan syarat ikatan yang ada, yang membatasinya berupa sumber daya yang tersedia, teknologi yang ada, kendala tujuan, dan sebagainya

5. Interpretasi Solusi Model.

6. Menyimpulkan hasil penelitian.

7. Selesai. 


\subsection{Perumusan Masalah Goal Programming}

Menurut Marpaung J. (2009) bahwa ada beberapa langkah yang harus dilakukan dalam perumusan masalah Goal Programming antara lain :

1. Penentuan variabel keputusan

Variabel yang akan diteliti adalah banyaknya penyaluran BBM $\left(X_{i 1}\right)$ Dimana $i=$ 1,2,3 yang mempresentasikan jenis-jenis BBM yaitu (1)Premium, (2)Pertamax, (3)Solar, (4) banyaknya truk pengangkut BBM untuk PT.PT. Arjuna M setia, (5) Mr.Lucky Lasahido, (6) PT. Trioceles utama.

2. Penentuan fungsi tujuan. Ada 4 macam fungsi tujuan dalam GP, yaitu 1). Meminimumkan $Z=\sum_{i=1}^{m}\left(d_{i}^{+}+d_{i}^{-}\right)$, 2). Meminimumkan $Z=\sum_{i=1}^{m} P_{k}\left(d_{i}^{+}+d_{i}^{-}\right)$untuk $k=1,2, \ldots, i \quad 3)$. Meminimumkan $Z=\sum_{i=1}^{m} W_{k i}\left(d_{i}^{+}+d_{i}^{-}\right)$untuk $\left.k=1,2, \ldots, i, 4\right)$. Meminimumkan $Z=\sum_{i=1}^{m} P_{k} W_{k i}\left(d_{i}^{+}+d_{i}^{-}\right)$untuk $k=1,2, \ldots$,

3. Penentuan prioritas utama

- Banyaknya penyaluran BBM kemasing-masing SPBU.

- Jumlah truk yang digunakan.

4. Penentuan fungsi pencapaian. Dalam memformulasikan fungsi pencapaian adalah menggabungkan Setiap tujuan yang berbentuk minimasi variabel simpangan sesuai dengan prioritasnya.

5. Penyelesaian model Goal Programming.

Adapun bentuk umum dari metode $G P$ adalah:

Meminimumkan $\quad Z=\sum_{i=1}^{n}\left(d_{i}^{+}+d_{i}^{-}\right)$

Kendalanya:

$$
\begin{aligned}
& \sum_{i=1}^{n} a_{i j} X_{j}-d_{i}^{+}+d_{i}^{-}=b_{i} \\
& j=1,2, \ldots, m \\
& k=1,2, \ldots, p \\
& m, n, p \in \mathbb{Z}^{+}
\end{aligned}
$$

Keterangan :

$X_{j} \quad$ : Peubah pengambilan keputusan atau kegiatan yang kini dinamakan sebagai sub tujuan

$C_{k} \quad$ : Jumlah sumber daya yang tersedia.

$a_{i j} \quad$ : Koefisien teknologi fungsi kendala tujuan, yaitu yang berhubungan dengan tujuan peubah pengambilan keputusan $X_{j}$

$b_{i} \quad$ : Tujuan atau target yang ingin dicapai

$d_{i}^{+}, d_{i}^{-}$: Deviasi plus dan minus dari tujuan atau target ke-i 


\section{HASIL DAN PEMBAHASAN}

\subsection{Hasil}

\subsubsection{Pengumpulan Data}

Data yang diperlukan dalam penelitian ini adalah kapasitas tangki SPBU yang berada di Poso Kota yakni SPBU PT. Triocelebes Utama, PT. Arjuna M Setia dan Mr. Lucky Lasahido serta persedian BBM dan kapasitas truk yang digunakan. Adapun data yang diperoleh yaitu :

\section{Kapasitas Tangki SPBU}

Tabel 1 : Data kapasitas tangki SPBU di Kota Poso

\begin{tabular}{|l|c|c|c|}
\hline \multirow{2}{*}{ Perusahaan } & \multicolumn{3}{|c|}{ Jenis BBM } \\
\cline { 2 - 4 } & $\begin{array}{c}\text { Premium } \\
\text { (liter) }\end{array}$ & $\begin{array}{c}\text { Solar } \\
\text { (liter) }\end{array}$ & $\begin{array}{c}\text { Pertamax } \\
\text { (liter) }\end{array}$ \\
\hline PT. Triocelebes Utama & 40.000 & 30.000 & 10.000 \\
\hline PT. Arjuna M Setia & 30.000 & 15.000 & 15.000 \\
\hline Mr. Lucky Lasahido & 29.000 & 14.000 & 14.000 \\
\hline Jumlah & 99.000 & 59.000 & 39.000 \\
\hline
\end{tabular}

Sumber : SPBU kota Poso

2. Jumlah dan Kapasitas Truk

Tabel 2 : Jumlah dan kapasitas truk PT. Pertamina Unit Pemasaran VII Terminal BBM Poso

\begin{tabular}{|l|c|c|c|}
\hline \multirow{2}{*}{ Kapasitas Truk } & \multicolumn{3}{|c|}{ Jumlah truk angkut } \\
\cline { 2 - 4 } & Premium & Solar & Pertamax \\
\hline $8.000 /$ & 3 & 2 & 1 \\
\hline $16.000 /$ & 1 & 1 & - \\
\hline Total & 4 & 3 & 1 \\
\hline
\end{tabular}

Sumber : PT. Pertamina Unit Pemasaran VII Terminal BBM Poso Group

\section{Persediaan BBM sesuai Kebutuhan}

Tabel 3 : Data persediaan BBM dikota Poso

\begin{tabular}{|l|l|l|l|l|}
\hline \multirow{2}{*}{ No } & \multirow{2}{*}{ Bulan } & \multicolumn{4}{l|}{ Prediksi kebutuhan BBM perbulan (liter) } \\
\cline { 3 - 5 } & & Premium & Pertamax & \multicolumn{2}{l|}{ Solar } \\
\hline 1 & Februari & $1.156 .000,00$ & $352.000,00$ & $964.000,00$ \\
\hline 2 & Maret & $1.58 .543,60$ & $349.317,70$ & $965.363,60$ \\
\hline 3 & April & $1.062 .195,50$ & $349.317,70$ & $966.727,20$ \\
\hline 4 & Mei & $1.064 .739,10$ & $349.317,70$ & $730.889,60$ \\
\hline 5 & Juni & $1.067 .282,70$ & $349.317,70$ & $732.253,20$ \\
\hline 6 & Juli & $1.069 .826,30$ & $349.317,70$ & $733.616,80$ \\
\hline 7 & Agustus & $1.072 .369,90$ & $349.317,70$ & $734.980,40$ \\
\hline 8 & September & $1.074 .913,50$ & $349.317,70$ & $736.344,00$ \\
\hline
\end{tabular}




\begin{tabular}{|l|l|l|l|l|}
\hline 9 & Oktober & $1.077 .457,10$ & $349.317,70$ & $737.707,60$ \\
\hline 10 & November & $1.080 .000,70$ & $349.317,70$ & $739.071,20$ \\
\hline 11 & Desember & $1.082 .544,30$ & $349.317,70$ & $740.434,80$ \\
\hline
\end{tabular}

\subsubsection{Formulasi Model Matematika Penyaluran BBM Ke Masing-Masing SPBU}

Penyaluran BBM merupakan suatu fungsi kendala dengan melihat keterkaitan antara persediaan dan kapasitas tangki SPBU. Penyaluran BBM perbulan diperoleh sebagai berikut Tabel 4 : Data permintaan BBM per Bulan di Kota Poso

\begin{tabular}{|c|c|}
\hline Jumlah & Kapasitas Tangki \\
\hline$b_{1}=462.400 l$ & $a_{11}=40.000 l$ \\
\hline$b_{2}=346.800 l$ & $a_{12}=30.000 l$ \\
\hline$b_{3}=346.800 l$ & $a_{13}=29.000 l$ \\
\hline$b_{4}=385.600 l$ & $a_{21}=30.000 l$ \\
\hline$b_{5}=289.200 l$ & $a_{22}=15.000 l$ \\
\hline$b_{6}=289.200 l$ & $a_{23}=14.000 l$ \\
\hline$b_{7}=140.800 l$ & $a_{31}=10.000 l$ \\
\hline$b_{8}=105.600 l$ & $a_{32}=15.000 l$ \\
\hline$b_{9}=105.600 l$ & $a_{33}=14.000 l$ \\
\hline
\end{tabular}

Sumber : SPBU Kota Poso

Dengan :

$a_{11}=$ Kapasitas tangki untuk premium

$a_{21}=$ Kapasitas tangki untuk solar

$a_{31}=$ Kapasitas tangki untuk pertamax

$b_{1}, b_{2}, b_{3} \quad=$ Jumlah permintaan premium perbulan

$b_{4}, b_{5}, b_{6}=$ Jumlah permintaan solar perbulan

$b_{7}, b_{8}, b_{9}=$ Jumlah permintaan pertamax perbulan

Persamaannya adalah :

$\sum_{i=1}^{m} a_{i j} X_{j}+d_{i}^{+}-d_{i}^{-}=b_{i}$

Dengan :

$X_{j}=$ Variabel keputusan

$b_{i}=$ Target atau tujuan

$a_{i j}=$ Koefisien fungsi kendala

$d_{i}^{+}=$variabel deviasi yang mempresentasekan tingkat pencapaian dibawah target terhadap tujuan $b_{i}$

$d_{i}^{+}=$variabel deviasi yang mempresentasekan tingkat pencapaian diatas target terhadap tujuan $b_{i}$ 


\subsubsection{Formulasi Model Matematika Jumlah truk}

Pengoptimalan jumlah truk merupakan suatu fungsi kendala dengan melihat keterkaitan antara pendistribusian BBM terhadap pertamina dan kapasitas truk yang digunakan. Formulasi model matematik jumlah truk terbagi atas 2 kapasitas muatan truk yaitu truk kapasitas 8.000 / dan 16.000 /. berdasarkan data pendistribusian BBM dan kapasitas muatan truk yang diperoleh adalah sebagai berikut :

\section{a. Premium}

Tabel 5 : Data kapasitas truk untuk premium

\begin{tabular}{|l|c|c|c|}
\hline \multicolumn{1}{|c|}{ Nama Pertamina } & $\begin{array}{c}\text { kapasitas truk } \\
8000 /\left(a_{1 i}\right)\end{array}$ & $\begin{array}{c}\text { kapasitas truk } \\
16000 /\left(a_{2 i}\right)\end{array}$ & $\begin{array}{c}\text { Kapasitas tangki } \\
\text { (liter) } \\
\text { (bi) }\end{array}$ \\
\hline Mr. Lucky Lasahido & $a_{41}=8000$ & $a_{51}=16000$ & $b_{10}=29.000$ \\
\hline $\begin{array}{l}\text { PT. Trioceles } \\
\text { Utama }\end{array}$ & $a_{42}=8000$ & $a_{52}=16000$ & $b_{11}=40.000$ \\
\hline PT. Arjuna M setia & $a_{43}=8000$ & $a_{53}=16000$ & $b_{12}=30.000$ \\
\hline
\end{tabular}

b. Solar

Tabel 6 : Data kapasitas truk untuk solar

\begin{tabular}{|l|c|c|c|}
\hline \multicolumn{1}{|c|}{ Pertamina } & $\begin{array}{c}\text { kapasitas truk } \\
8000 l\left(a_{1 i}\right)\end{array}$ & $\begin{array}{c}\text { kapasitas truk } \\
16000 l\left(a_{2 i}\right)\end{array}$ & solar (bi) \\
\hline Mr. Lucky Lasahido & $a_{15}=8000$ & $a_{25}=16000$ & $b_{5}=14000$ \\
\hline PT. Trioceles Utama & $a_{16}=8000$ & $a_{26}=16000$ & $b_{6}=30000$ \\
\hline PT. Arjuna M setia & $a_{17}=8000$ & $a_{27}=16000$ & $b_{7}=15000$ \\
\hline
\end{tabular}

\section{c. Pertamax}

Tabel 7 : Data Kapasitas Truk Untuk Pertamax

\begin{tabular}{|l|c|c|c|}
\hline \multicolumn{1}{|c|}{ Pertamina } & $\begin{array}{c}\text { kapsitas truk } \\
8000 \mathrm{I}\left(a_{1 i}\right)\end{array}$ & $\begin{array}{c}\text { kapsitas truk } \\
16000 \mathrm{I}\end{array}$ & pertamax (bi) \\
\hline Mr. Lucky Lasahido & $a_{18}=8000$ & - & $b_{8}=14000$ \\
\hline $\begin{array}{l}\text { PT. Trioceles } \\
\text { Utama }\end{array}$ & $a_{19}=8000$ & - & $b_{9}=10000$ \\
\hline PT. Arjuna M setia & $a_{110}=8000$ & - & $b_{10}=15000$ \\
\hline
\end{tabular}


dengan :

$b_{2}$ : Pendistribusian premium di pertamina Mr. Lucky Lasahido per bulan

$b_{3}$ : Pendistribusian premium di pertamina PT. Trioceles Utama per bulan

$b_{4}$ : Pendistribusian premium di pertamina PT. Arjuna setia per bulan

$b_{5}$ : Pendistribusian solar di pertamina Mr. Lucky Lasahido per bulan

$b_{6}$ : Pendistribusian solar dipertamina PT. Trioceles Utama per bulan

$b_{7}$ : Pendistribusian solar di pertamina PT. Arjuna M setia per bulan

$b_{8}$ : Pendistrbusian pertamax dipertamina Mr. Lucky Lasahido per bulan

$b_{9}$ : Pendistrbusian pertamax di pertamina PT. Trioceles Utama per bulan

$b_{10}$ :Pendistribusian pertamax di pertamina PT. Arjuna M setia per bulan

$a_{1 i}:$ Truk berkapasitas $8.000 \mathrm{l}$

$a_{2 i}:$ Truk berkapasitas $16.000 l$

Fungsi persamaannya adalah :

$\sum_{i=1}^{m} a_{i j} X_{j}+d_{i}^{+}-d_{i}^{-}=b_{i}$

Dengan :

$X_{j} \quad=$ Variabel keputusan

$b_{i} \quad=$ Target atau tujuan

$a_{i j} \quad=$ Koefisien fungsi kendala tujuan

$d_{i}^{+} \quad=$ variabel deviasi yang mempresentasekan tingkat pencapaian dibawah target terhadap tujuan $b_{i}$

3.1.4. Menentukan Prioritas Utama dan Pritoritas Tujuan.

Adapun prioritas utama dan urutannya, yaitu :

Prioritas $1\left(P_{1}\right) \quad$ : Banyaknya penyaluran premium.

Prioritas $2\left(P_{2}\right) \quad$ : Banyaknya penyaluran solar

Prioritas $3\left(P_{3}\right) \quad$ : Banyaknya penyaluran pertamax.

Prioritas $4\left(P_{4}\right) \quad$ : Target jumlah truk yang digunakan untuk distribusi Premium di Mr. Lucky lasahido.

Prioritas $5\left(P_{5}\right) \quad$ : Target jumlah truk yang digunakan untuk distribusi solar di Mr. Lucky lasahido.

Prioritas $6\left(P_{6}\right) \quad$ : Target jumlah truk yang digunakan untuk distribusi Pertamax di Mr. Lucky lasahido.

Prioritas $7\left(P_{7}\right) \quad$ : Target jumlah truk yang digunakan untuk distribusi premium di PT.Trioceles Utama.

Prioritas $\left(P_{8}\right) \quad$ : Target jumlah truk yang digunakan untuk distribusi solar di PT.Trioceles Utama. 
Prioritas $9\left(P_{9}\right) \quad$ : Target jumlah truk yang digunakan untuk distribusi pertamax di PT.Trioceles Utama.

Prioritas $10\left(P_{10}\right) \quad$ : Target jumlah truk yang digunakan untuk distribusi premium PT. Arjuna M setia.

Prioritas $11\left(P_{11}\right) \quad$ : Target jumlah truk yang digunakan untuk distribusi solar PT. Arjuna $M$ setia.

Prioritas $12\left(P_{12}\right) \quad$ : Target jumlah truk yang digunakan untuk distribusi pertamax PT. Arjuna M setia.

Dan fungsi tujuan dinyatakan sebagai berikut :

Untuk prioritas 1 , variable yang digunakan yaitu $d_{1}^{-}$dan $d_{1}^{+}$ditulis : $p_{1}\left(d_{1}^{+}+d_{1}^{-}\right)$ Untuk prioritas 2 , variable yang digunakan yaitu, $d_{2}^{-}$dan $d_{2}^{+}$ditulis : $p_{2}\left(d_{2}^{+}+d_{2}^{-}\right)$ Untuk prioritas 3 , variable yang digunakan yaitu, $d_{3}^{-}$dan $d_{3}^{+}$ditulis : $p_{3}\left(d_{3}^{+}+d_{3}^{-}\right)$ Untuk prioritas 4 , variable yang digunakan yaitu, $d_{4}^{-}$dan $d_{4}^{+}$ditulis : $p_{4}\left(d_{4}^{+}+d_{4}^{-}\right)$ Untuk prioritas 5 , variable yang digunakan yaitu, $d_{5}^{-}$dan $d_{5}^{+}$ditulis : $p_{5}\left(d_{5}^{+}+d_{5}^{-}\right)$ Untuk prioritas 6 , variable yang digunakan yaitu, $d_{6}^{-}$dan $d_{6}^{+}$ditulis : $p_{6}\left(d_{6}^{+}+d_{6}^{-}\right)$ Untuk prioritas 7 , variable yang digunakan yaitu $d_{7}^{-}$dan $d_{7}^{+}$ditulis $: p_{7}\left(d_{7}^{+}+d_{7}^{-}\right)$ Untuk prioritas 8 , variable yang digunakan yaitu $d_{8}^{-}$dan $d_{8}^{+}$ditulis : $p_{8}\left(d_{8}^{+}+d_{8}^{-}\right)$ Untuk prioritas 9 , variable yang digunakan yaitu $d_{9}^{-}$dan $d_{9}^{+}$ditulis : $p_{9}\left(d_{9}^{+}+d_{9}^{-}\right)$ Untuk prioritas 10 , variable yang digunakan yaitu $d_{10}^{-}$dan $d_{10}^{+}$ditulis : $p_{10}\left(d_{10}^{+}+d_{10}^{-}\right)$ Untuk prioritas 11 , variable yang digunakan yaitu $d_{11}^{-}$dan $d_{11}^{+}$ditulis : $p_{11}\left(d_{11}^{+}+d_{11}^{-}\right)$ Untuk prioritas 12 , variable yang digunakan yaitu $d_{12}^{-}$dan $d_{12}^{+}$ditulis $: p_{12}\left(d_{12}^{+}+d_{12}^{-}\right)$

\subsubsection{Fungsi Tujuan dan Fungsi Kendala}

Setelah menentukan prioritas dan urutannya, fungsi tujuan yang terbentuk adalah :

Minimumkan

$$
\begin{aligned}
= & p_{1}\left(d_{1}^{+}+d_{1}^{-}\right)+p_{2}\left(d_{2}^{+}+d_{2}^{-}\right)+p_{3}\left(d_{3}^{+}+d_{3}^{-}\right)+p_{4}\left(d_{4}^{+}+d_{4}^{-}\right)+ \\
& p_{5}\left(d_{5}^{+}+d_{5}^{-}\right)+p_{6}\left(d_{6}^{+}+d_{6}^{-}\right)+p_{7}\left(d_{7}^{+}+d_{7}^{-}\right)+p_{8}\left(d_{8}^{+}+d_{8}^{-}\right)+ \\
& p_{9}\left(d_{9}^{+}+d_{9}^{-}\right)+p_{10}\left(d_{10}^{+}+d_{10}^{-}\right)+p_{11}\left(d_{11}^{+}+d_{11}^{-}\right)+p_{12}\left(d_{12}^{+}+d_{12}^{-}\right)
\end{aligned}
$$

Fungsi Kendala :

1. Kendala tujuan 1 (banyaknya penyaluran BBM ke masing-masing SPBU)

$$
\begin{aligned}
& 40.000 X_{1}+d_{1}^{-}-d_{1}^{+}=462.400 l \\
& 30.000 X_{2}+d_{2}^{-}-d_{2}^{+}=346.800 l \\
& 29.000 X_{3}+d_{3}^{-}-d_{3}^{+}=346.800 l \\
& 30.000 X_{4}+d_{4}^{-}-d_{4}^{+}=385.600 l \\
& 15.000 X_{5}+d_{5}^{-}-d_{5}^{+}=289.200 l \\
& 14.000 X_{6}+d_{6}^{-}-d_{6}^{+}=289.200 l \\
& 10.000 X_{7}+d_{7}^{-}-d_{7}^{+}=140.800 l \\
& 15.000 X_{8}+d_{8}^{-}-d_{8}^{+}=105.600 l
\end{aligned}
$$




$$
14.000 X_{9}+d_{9}^{-}-d_{9}^{+}=105.600 l
$$

2. Kendala tujuan 2 (truk berkapasitas muatan 8.000 untuk premium)

$$
\begin{aligned}
& 8.000 X_{10}+d_{10}^{-}-d_{10}^{+}=40.000 l \\
& 8.000 X_{11}+d_{11}^{-}-d_{11}^{+}=30.000 l \\
& 8.000 X_{12}+d_{12}^{-}-d_{12}^{+}=29.000 l
\end{aligned}
$$

3. Kendala tujuan 3 (truk kapasitas muatan 16.000 untuk premium )

$$
\begin{aligned}
& 16.000 X_{10}+d_{10}^{-}-d_{10}^{+}=40.000 \\
& 16.000 X_{11}+d_{11}^{-}-d_{11}^{+}=30.000 \\
& 16.000 X_{12}+d_{12}^{-}-d_{12}^{+}=29.000
\end{aligned}
$$

4. Kendala tujuan 4 (truk berkapasitas muatan 8.000 untuk solar )

$$
\begin{aligned}
& 8.000 X_{13}+d_{13}^{-}-d_{13}^{+}=30.000 \\
& 8.000 X_{14}+d_{14}^{-}-d_{14}^{+}=15.000 \\
& 8.000 X_{15}+d_{15}^{-}-d_{15}^{+}=14.000
\end{aligned}
$$

5. Kendala tujuan 5 (truk kapasitas muatan 16.000 untuk solar)

$$
\begin{aligned}
& 16.000 X_{13}+d_{13}^{-}-d_{13}^{+}=30.000 \\
& 16.000 X_{14}+d_{14}^{-}-d_{14}^{+}=20.000 \\
& 16.000 X_{15}+d_{15}^{-}-d_{15}^{+}=20.000
\end{aligned}
$$

6. Kendala tujuan 2 (truk berkapasitas muatan 8.000 untuk pertamax )

$$
\begin{aligned}
& 8.000 X_{16}+d_{16}^{-}-d_{16}^{+}=10.000 \\
& 8.000 X_{17}+d_{17}^{-}-d_{17}^{+}=15.000 \\
& 8.000 X_{18}+d_{18}^{-}-d_{18}^{+}=14.000
\end{aligned}
$$

Kendala non negatif :

$X_{1}, X_{2}, X_{3}, X_{4}, X_{5}, X_{6}, X_{7}, X_{8}, X_{9}, X_{10}, X_{11}, X_{12}, X_{13}, X_{14}, X_{15}, X_{16}, X_{17}, X_{18}$, $d_{1}^{-}, d_{2}^{-}, d_{3}^{-}, d_{4}^{-}, d_{5}^{-}, d_{6}^{-}, d_{7}^{-}, d_{8}^{-}, d_{9}^{-} d_{11}^{-}, d_{12}^{-}$,

$d_{13}^{-}, d_{14}^{-}, d_{15}^{-}, d_{16}^{-}, d_{17}^{-}, d_{18}^{-}, d_{1}^{+}, d_{2}^{+}, d_{3}^{+}, d_{4}^{+}, d_{5}^{+}, d_{6}^{+}, d_{7}^{+}, d_{8}^{+}$,

$d_{9}^{+}, d_{10}^{+}, d_{11}^{+}, d_{12}^{+}, d_{13}^{+}, d_{14}^{+}, d_{15}^{+}, d_{16}^{+}, d_{17}^{+}, d_{18}^{+} \geq 0$ dengan :

$X_{1} \quad$ : Banyaknya penyaluran premium di PT. Trioceles Utama

$X_{2}$ : Banyaknya penyaluran premium di PT. Arjuna M. setia

$X_{3} \quad$ : Banyaknya penyaluran pertamax di PT. Mr. Lucky lasahido

$X_{4} \quad$ : Banyaknya penyaluran premium di PT. Trioceles Utama.

$X_{5} \quad$ : Banyanknya penyaluran solar di PT.Arjuna M. Setia

$X_{6} \quad$ : Banyaknya penyaluran pertamax di PT. Mr. Lucky lasahido

$X_{7} \quad$ : Banyaknya penyaluran premium di PT. Trioceles Utama.

$X_{8} \quad$ : Banyaknya penyaluran solar di PT.Arjuna M. Setia

$X_{9} \quad$ : Banyaknya penyaluran pertamax di PT. Mr. Lucky lasahido

$X_{10} \quad$ : Banyaknya truk pengangkut premium di PT. Trioceles Utama

$X_{11}$ : Banyaknya truk pengangkut premium di PT.Arjuna M. Setia

$X_{12} \quad$ : Banyaknya truk pengangkut premium di PT. Mr. Lucky lasahido

$X_{13}$ : Banyaknya truk pengangkut solar di PT. Mr. Trioceles Utama 
$X_{14}$ : Banyaknya truk pengangkut solar di PT.Arjuna M. Setia

$X_{15} \quad$ : Banyaknya truk pengangkut solar di PT. Mr. Lucky lasahido

$X_{16}$ : Banyaknya truk pengangkut pertamax di PT. Trioceles Utama .

$X_{17} \quad$ : Banyaknya truk pengangkut pertamax di PT.Arjuna M. Setia

$X_{18}$ : Banyaknya truk pengangkut pertamax di PT. Mr. Lucky lasahido

$a_{11}, a_{12}, a_{13} \quad$ : Kapasitas tangki premium

$a_{14}, a_{15}, a_{16} \quad$ : Kapasitas tangki solar

$a_{17}, a_{18}, a_{19} \quad$ : Kapasitas tangki pertamax

$d_{1}^{-}, d_{2}^{-} \ldots d_{18}^{-} \quad$ : Penyaluran BBM yang ditetapkan di atas terget

$d_{1}^{+}, d_{2}^{+} \ldots d_{18}^{+} \quad$ : Penyaluran BBM yang ditetapkan dibawah target

\subsubsection{Penyelesaian Model Matematis Goal Programming}

langkah - langkah untuk menyelesaikan model Goal Programming yaitu :

a. Membentuk tabel simpleks awal.

Memasukan nilai-nilai fungsi kendala kedalam tabel simpleks.

b. Pilih kolom kunci dimana $C_{j}-Z_{j}$ memiliki nilai negatif terbesar.

c. Pilih baris kunci yang berpedoman pada $b_{i} / a_{i j}$ dengan rasio terkecil.

d. Mencari sistem kanonikal yaitu sistem dimana nilai elemen pivot bernilai 1 dan elemen lain bernilai nol dengan cara menggunakan Operasi Baris Elementer (OBE), Dengan demikian diperoleh tabel simpleks iterasi i.

e. Pemeriksaaan optimalitas, yaitu melihat apakah solusi sudah layak atau tidak. Solusi dikatakan layak bila variabel adalah positif atau nol. $\left(C_{j}-Z_{j} \geq 0\right)$.

\subsubsection{Penyelesaian masalah matematis Goal Programming.}

Goal Programming pertama kali diperkenalkan oleh Charnes dan Cooper (1961). Pada iterasi 1 nilai pada baris $C_{j}-Z_{j}<0$, sehingga dikatakan solusi belum optimal. Sehingga perhitungan akan dilanjutkan sampai mendapatkan nilai yang layak atau optimal. $\left(C_{j}-Z_{j} \geq 0\right)$. Penyelesaian perhitungan Goal Programming akan dibantu dengan menggunakan Software QM for windows.

\subsubsection{Penyelesaian Masalah Goal Programming menggunakan QM for windows}

QM for windows merupakan aplikasi yang dirancang untuk melakukan perhitungan yang diperlukan pihak manajemen untuk mengambil keputusan baik bidang produksi maupun pemasaran. Software ini dirancang oleh Howard J. Weiss (1996), untuk membantu penyusunan perkiraan anggaran untuk produksi bahan baku menjadi produk jadi atau setengah jadi pada produk pabrikasi. (Fauji,2015). 
a. Memasukkan nilai fungsi kendala dan tujan kedalam tabel

1. Fungsi Kendala 1 (banyaknya Penyaluran BBM ke masing-masing SPBU)

\begin{tabular}{|c|c|c|c|c|c|c|c|c|c|c|c|c|c|c|}
\hline \multicolumn{15}{|c|}{ (unitited) } \\
\hline & $W^{\prime}(d+)$ & Prty $(d+)$ & $W t(d-)$ & Ptyy(d-) & $x_{1}$ & $\times 2$ & $x_{3}$ & X4 & X5 & $X 6$ & $\mathrm{X} 7$ & $\mathrm{X8}$ & $\times 9$ & RHS \\
\hline GoalCnstmt 1 & 1 & 1 & 1 & 1 & 40000 & 0 & 0 & 0 & 0 & 0 & 0 & 0 & $0=$ & 462400 \\
\hline GoalCnstint2 & 1 & 2 & 1 & 2 & 0 & 30000 & 0 & 0 & 0 & 0 & 1 & 0 & $0=$ & 346800 \\
\hline GoalCnstmt 3 & 1 & 3 & 1 & 3 & 0 & 0 & 29000 & 0 & 0 & 0 & 0 & 0 & $0=$ & 346800 \\
\hline GoalCnstint 4 & 1 & 4 & 1 & 4 & 0 & 0 & 0 & 30000 & 0 & 0 & 0 & 0 & $0=$ & 385600 \\
\hline GoalCnstmt 5 & 1 & 5 & 1 & 5 & 0 & 0 & 0 & 0 & 15000 & 0 & 0 & 0 & $0=$ & 289200 \\
\hline GoalCnstmt 6 & 1 & 6 & 1 & 6 & 0 & 0 & 0 & 0 & 0 & 14000 & 0 & 0 & $0=$ & 289200 \\
\hline GoalCnstmt7 & 1 & 7 & 1 & 7 & 0 & 0 & 0 & 0 & 0 & 0 & 10000 & 0 & $0=$ & 140800 \\
\hline GoalCnstmt 8 & 1 & 8 & 1 & 8 & 0 & 0 & 0 & 0 & 0 & 0 & 0 & 15000 & $0=$ & 105600 \\
\hline GoalCnstmt9 & 1 & 9 & 1 & 9 & 0 & 0 & 0 & 0 & 0 & 0 & 0 & 0 & $14000=$ & 105600 \\
\hline
\end{tabular}

Gambar 1 : Tabel Fungsi Kendala 1

\section{Hasil Fungsi Kendala 1}

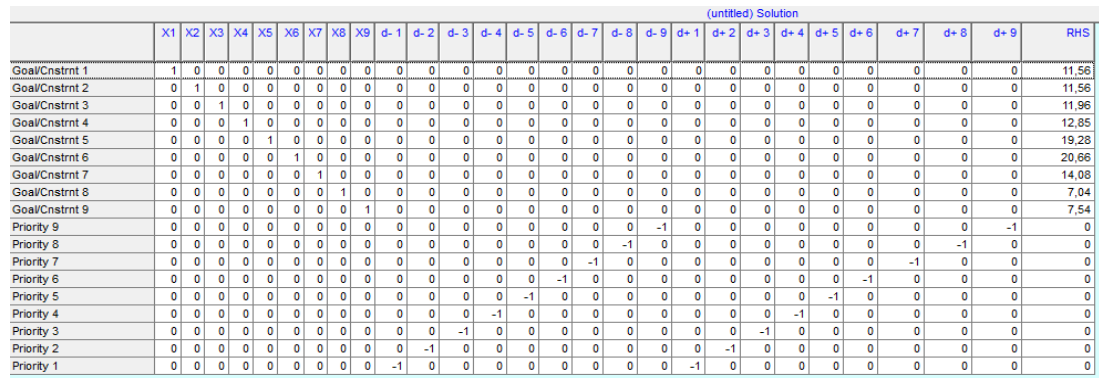

Gambar 2 : Hasil Fungsi Kendala 1

\subsection{Pembahasan}

Persediaan BBM dilakukan untuk memenuhi penyaluran BBM maupun sebagai cadangan agar tidak terjadi kekurangan. Dari hasil penyelesaian diatas dengan menggunakan metode Goal Programming didapatkan persediaan BBM berdasarkan kapasitas Tangki SPBU dapat memenuhi penyaluran BBM selama 1 bulan dengan jumlah persediaan sebesar 1.156.000 I untuk premium, 352.000 I untuk solar, dan 96.000 I untuk pertamax dimana kapasitas tangki total yang ada di 3 pertamina di kota poso yaitu 99.000 I untuk premium, 59.000 I untuk solar, dan 39.000 I untuk pertamax.

\section{KESIMPULAN}

Berdasarkan hasil penelitian dan uraian-uraian pada bab-bab sebelumnya, maka dapat disimpulkan bahwa:

1. Maksimal persediaan BBM berdasarkan kapasitas Tangki SPBU di Kota Poso dapat memenuhi penyaluran BBM selama 1 bulan dengan jumlah persediaan sebesar $1.156 .000 \mathrm{I}$ untuk premium, sedangkan untuk solar $964.000 \mathrm{I}$, dan $352.000 \mathrm{I}$ untuk pertamax. 
2. Jumlah truk optimal untuk pendistribusian BBM ke SPBU di Kota Poso adalah sebanyak 9 unit untuk premium, terdiri dari 5 unit truk berkapasitas 8000 I dan 4 unit truk berkapasitas 16.000

I. Sedangkan untuk pendistribusian Solar sebanyak 4 unit truk berkapasitas $16.000 \mathrm{I}$. dan Pertamax sebanyak 6 unit truk berkapasitas $8.000 \mathrm{I}$.

\section{DAFTAR PUSTAKA}

[1]. Ariadji, T., 2014, Distribusi Merupakan Permasalahan Utama BBM Bersubsidi, www.itb.ac.id. (Diakses pada tanggal 23 Maret 2015).

[2]. Charnes, A., dan W.W. Cooper., 1961, Management Models and Industrial Applications of linear Programming. Vol.1. JhonWiley and Sons, Inc New York.

[3]. Fauji, M., 2015, Penerapan Metode Goal Programming Untuk Mengoptimalkan persediaan BBm di Kota Poso Berbasis Peningkatan Kenderaan, Fakultas MIPA Universitas Tadulako.

[4]. Howard, J. Weiss., 1996, Manual POM - QM For Windows Version 3 Software For Decision Sciences : Quantitative Methods, Production and Operations.

[5]. Marpaung, J., 2009. Perencanaan Produksi yang Optimal dengan Pendekatan Goal Programming di PT. Gold Koin Indonesia, Fakultas Teknik Universitas Sumatera Utara. 